\title{
Trombocitopenia severa como manifestación de un tumor testicular de células germinales con metástasis cardíaca intracavitaria
}

\author{
Germán Armijo ; Patricio Sanhueza ${ }^{2}$; Marcelo Morales ${ }^{2}$; Claudio de la Vega ${ }^{1}$; Alejandro Ceballos ${ }^{3}$, \\ Carlos Orfalit. \\ 1. Residente de Cardiología. \\ 2. Cardiólogo. \\ 3. Residente de Medicina Interna. \\ 4. Cardiocirujano \\ Servicio de Cardiología. Hospital San Juan de Dios. Universidad de Chile.
}

Se describe el caso de un hombre de 24 años que se presenta con Púrpura trombocitopénico, cuyo estudio ecocardiográfico y tomografía computada demostró masa tumoral ocupando las cavidades derechas. Se evidenció posteriormente un tumor testicular izquierdo con componentes de seminoma y teratoma. Se resecó el tumor testicular y posteriormente el tumor intracardíaco, con normalización del recuento plaquetario.

Correspondencia:

Dr. Germán Armijo

garmijo.md@gmail.com 


\section{Testicular tumor with intracardiac metastasis presenting as severe thrombocytopenia}

A 24 year old man presented with severe thrombocytopenia. An intracardiac mass was shown to be a metastasis from a malignant testicular tumor. Resection of the primary tumor and the intracardiac metastasis led to full recovery of thrombocytopenia.

Keywords: testicular tumor, intracardiac metastasis, thrombocytopenia

\section{Introducción:}

Las neoplasias testiculares representan el $1 \%$ del total de las neoplasias en hombres, sin embargo, corresponden al carcinoma más común en el grupo de pacientes entre 15 a 35 años junto con la leucemia y el linfoma. El tumor de células germinales corresponde al $90 \%$ del total de las neoplasias testiculares, siendo excepcional las metástasis cardíacas. ${ }^{1}$

Se presenta - según nuestra revisión - el primer caso publicado en el país de un tumor testicular de células germinales con metástasis a cavidades derechas que debuta como trombocitopenia severa.

\section{Caso clínico:}

Hombre de 24 años, que debuta con síndrome purpúrico sospechándose Púrpura trombocitopénico idiopático por lo cual se encontraba en tratamiento esteroidal (Prednisona, hasta $1 \mathrm{mg} / \mathrm{kg} / \mathrm{día}$ ) hace 6 meses con mala respuesta a la

terapia y persistencia de trombocitopenias severas de alrededor de 10.000 plaquetas / Ml. No tenía historia familiar de relevancia ni uso concomitante de otros fármacos. Sin historia de compromiso de estado general o fiebre destacando, sin embargo, limitación funcional con disnea a esfuerzos moderados durante los últimos 3 meses, ortopnea., edema de cara, tronco, extremidades superiores y al menos 2 episodios de síncopes posturales. Fue hospitalizado en forma electiva en un Hospital Regional para probable esplenectomía terapéutica pero, tras su evaluación clínica se evidenció un paciente en buenas condiciones generales, sin síntomas o signos respiratorios, normotenso, con ritmo regular de 70x`, edema leve de tronco superior, y un soplo diastólico en foco tricúspide II/VI no irradiado. La radiografía de tórax fue normal y el electrocardiograma de reposo mostraba sólo bloqueo incompleto de rama derecha. Se realizó un ecocardiograma que reveló una gran masa tumoral intracavitaria que comprometía las cavidades de- 
rechas, con dilatación de estas, con extensión al tracto de salida del ventrículo derecho, asociado a derrame pericárdico leve a moderado y disfunción ventricular izquierda leve (Figura 1).

Trasladado a nuestra unidad para completar estudio y eventual cirugía cardíaca, evolucionó en regulares condiciones generales con trombocitopenia severa refractaria a esteroides a dosis altas, transfusiones y factores estimuladores de colonias plaquetarias.

Se complementó el estudio con TAC de cerebro, tórax, abdomen y pelvis que confirmó una gran masa intracavitaria derecha que se extendía hacia la vena cava superior, tronco venoso braquiocefálico izquierdo y el segmento visible de la vena yugular interna izquierda, dilatación leve de vena cava inferior y suprahepáticas, y adenopatías retroperitoneales confluyentes conformando una masa paraaórtica izquierda de 7 x $5,7 \mathrm{~cm}$.

En presencia de estos antecedentes se sospechó tumor testicular confirmado por estudio ecográfico que mostraba una masa testicular izquierda de $14 \times 7 \mathrm{~mm}$ y hernia inguinal izquierda. De sus marcadores tumorales, resultaron elevados la alfafetoproteina y la beta gonadotrofina coriónica humana. Se procedió a orquiectomía radical izquierda cuyo estudio confirmó neoplasia maligna de células germinales de tipo mixto, con componentes de seminoma clásico y teratoma. En los días posteriores el paciente evolucionó con deterioro general y síndrome de vena cava superior y se decidió efectuar cirugía cardíaca con circulación extracorpórea, a pesar de su trombocitopenia, extirpando la masa intracardíaca.

Su evolución post operatoria fue buena, con normalización inmediata de recuento plaquetario que se mantuvo hasta el alta (Gráfico 1).
El estudio histopatológico de la masa cardíaca demostró un carcinoma embrionario con células de tipo sinciciotrofoblasto, con áreas de tumor viable y zonas de tumor necrosado asociado a gran cantidad de fibrina (Figura 2). El control ecocardiográfico post operatorio demostró una imagen residual a nivel del ápex del ventrículo derecho, dilatación de cavidades derechas con reflujo tricuspídeo severo y normalización de función ventricular izquierda. El paciente fue dado de alta en buenas condiciones generales, asintomático en lo cardiovascular, iniciando quimioterapia con buena tolerancia.

\section{Discusión:}

Los tumores testiculares corresponden al 1\% de las neoplasias en hombres, siendo la neoplasia más frecuente en el grupo de pacientes entre 15 a 35 años junto con la leucemia y el linfoma. Un $90 \%$ corresponde a tumores de células germinales, donde un 50\% son seminomas (pacientes mayores) y la otra parte a tumores no seminomas, dentro de los cuales destacan el carcinoma embrionario, teratoma, teratocarcinoma, coriocarcinoma y tumores mixtos, estos últimos lo más frecuentes. ${ }^{1}$

Los tumores testiculares tienen la más alta sobrevida de todas las neoplasias malignas. En ausencia de metástasis a distancia la sobrevida a 5 años se estima en $96 \%$, pero cae a $60 \%$ en caso de metástasis a distancia, lográndose altas tasas de curación incluso en casos avanzados. ${ }^{2}$

En orden decreciente las metástasis pueden ocurrir a los linfonodos retroperitoneales, al pulmón, hígado, linfonodos mediastínicos, cerebro, riñones, tracto gastrointestinal y hueso, siendo excepcional la metástasis cardíaca. ${ }^{3}$

El primer registro de un tumor testicular de células germinales (teratoma) con metástasis cardíaca intracavitaria data
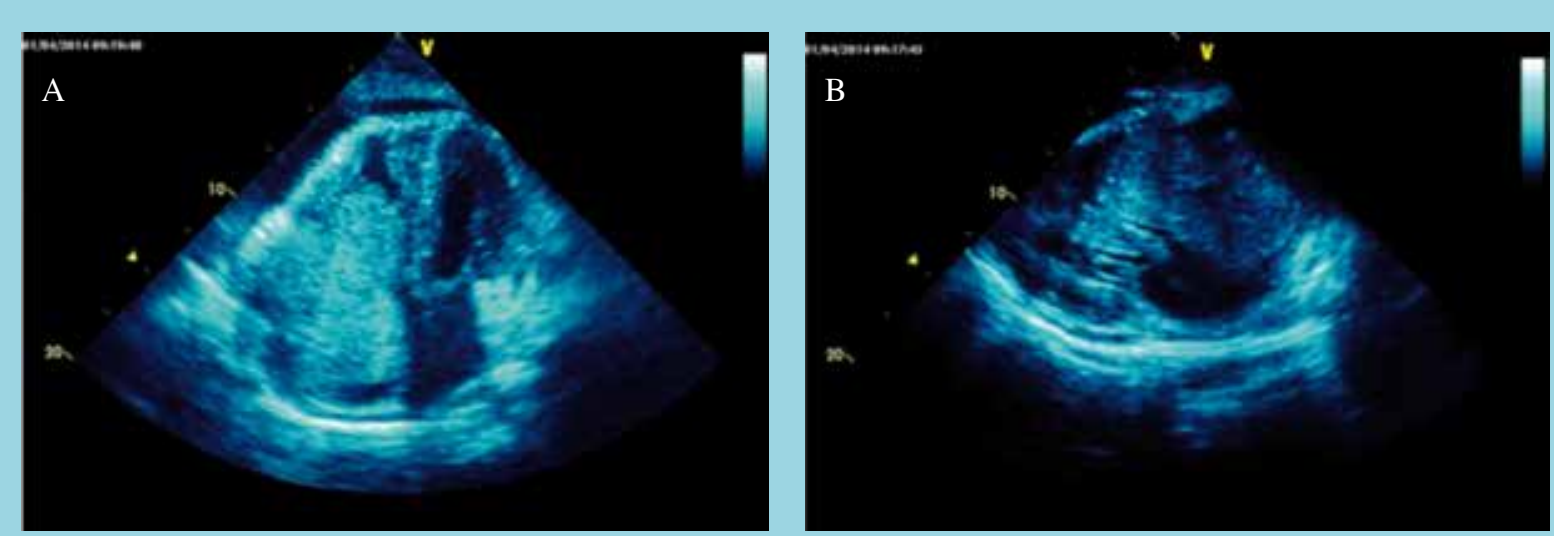

Figura $N^{\circ} 1$. Ecocardiograma (A) Eje apical 4 cámaras: Gran masa que compromete aurícula y ventrículo derecho, con aplanamiento de septum interventricular y derrame pericárdico. (B) Eje largo paraesternal: Se aprecia además el compromiso sobre las cavidades izquierdas. 


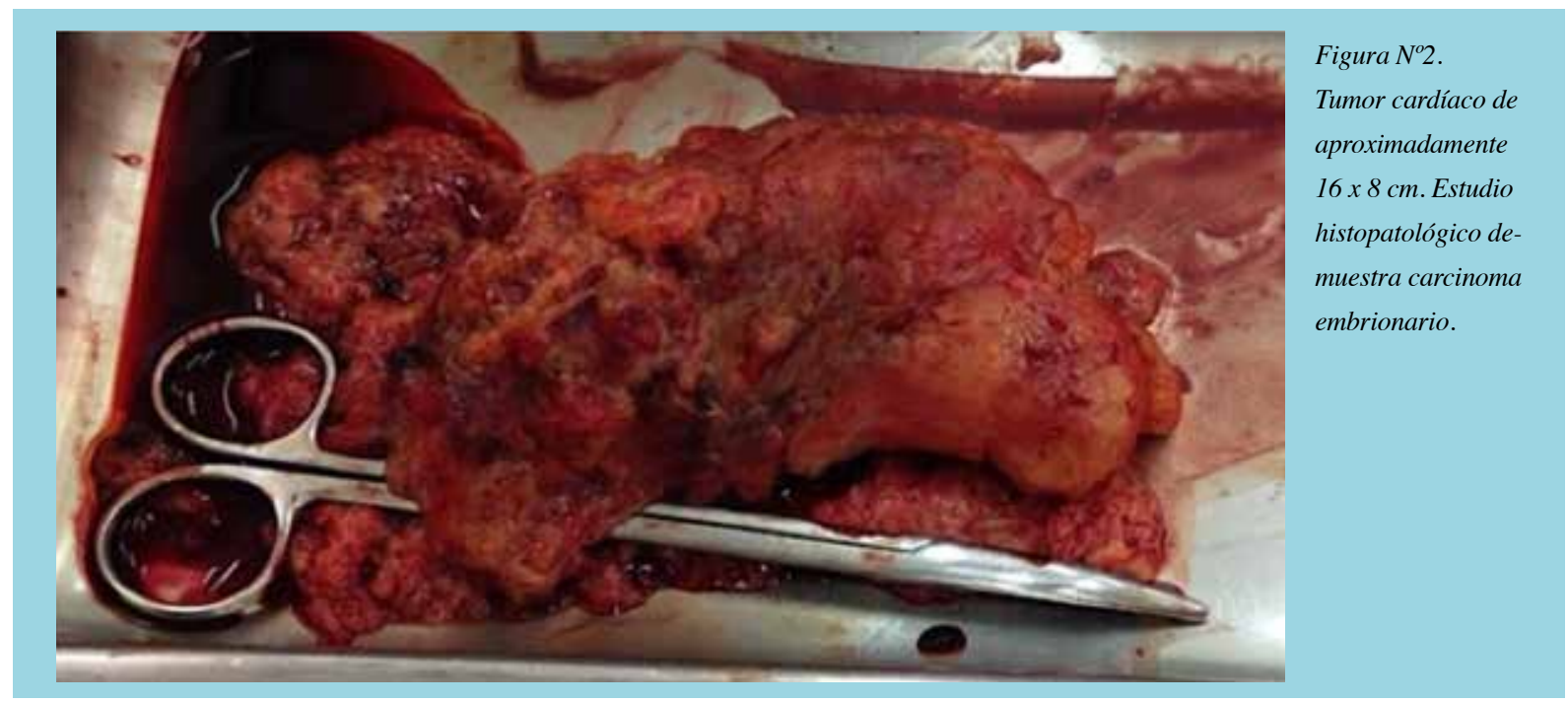

de un estudio de autopsia de Coates en 1822, existiendo además un segundo registro de autopsias de 154 pacientes con tumores testiculares (incluido seminomas) reportado por Bredael et al, donde se identificó 3 pacientes con metástasis cardíaca y 2 al pericardio. ${ }^{1-4}$

Las metástasis testiculares con compromiso intracavitario es un hecho poco frecuente con una incidencia reportada de $3,8 \%$ y ocurre fundamentalmente vía hematógena a través de la vena cava inferior. ${ }^{5}$ La mayoría de los carcinomas testiculares presentan una progresión ordenada y predecible que depende de la lateralidad del tumor original: a la cadena paraaórtica izquierda en caso de los tumores del lado izquierdo y a los linfonodos alrededor de la vena cava en el lado derecho y finalmente a la fosa supraclavicular mediante el conducto torácico. Sin embargo, el grupo de tumores no seminomas tiene mayor propensión a una progresión no contigua y a metástasis hematógenas. ${ }^{6}$
La extensión al corazón por un gran tumor trombótico de neoplasias de células germinales ha sido descrito en alrededor de 27 casos en la literatura internacional y no existen reportes en nuestro país.

Los síntomas más frecuentes corresponden a manifestaciones de insuficiencia cardíaca derecha, disnea, dolor torácico, hipotensión, soplo sistólico, desviación del eje a derecha, bloqueo de rama derecha y muy excepcionalmente síncope. ${ }^{1}$ Dentro de las principales potenciales complicaciones de una masa tumoral de las cavidades derechas se encuentra el riesgo de embolia pulmonar, hipertensión pulmonar aguda y muerte. ${ }^{7}$

En relación al tratamiento de los tumores testiculares depende del estadío en que se encuentren al momento del diagnóstico. En términos generales el diagnóstico histológico se establece mediante la orquidectomía correspondiente y la etapificación se completa con estudio de

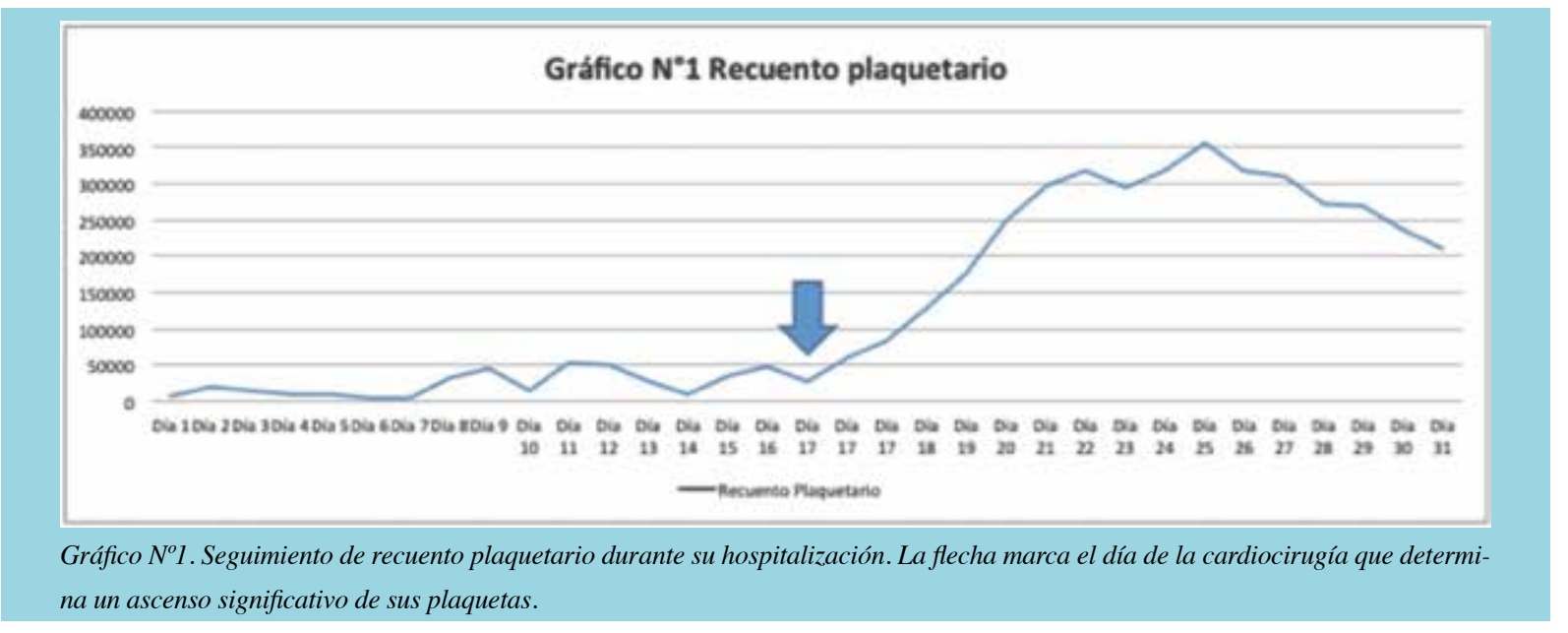


imágenes, habitualmente TAC. Los tumores con metástasis son tratados en su gran mayoría inicialmente con quimioterapia. Cuando no hay respuesta a la quimioterapia o la respuesta es parcial se completa el tratamiento con la resección de las masas residuales postquimioterapia. Sin embargo, una proporción considerable persiste con una masa "bulky" residual. El pronóstico a largo plazo post metasectomía dependerá del tipo histológico y de lo completo de la resección. ${ }^{1}$

Existen en la literatura sólo 3 casos similares a este que presentaron compromiso hematológico dado por anemia hemolítica y trombocitopenia, de los cuales 1 mejoró con la quimioterapia y los otros 2 pacientes fueron a resección quirúrgica por persistencia de anemia o trombocitopenia. ${ }^{1}$ -8 El mecanismo propuesto de la hemólisis sería similar al de las válvulas protésicas, como resultado de un trauma mecánico por contacto con material extraño, o daño estructural mediado por el shear stress asociado a flujo turbulento, estando bien documentada la activación y destrucción plaquetaria debido a este último mecanismo, que induciría además la agregación plaquetaria mediada por el factor de Von Willebrand.9-10 Este mecanismo es el que sospechó en nuestro paciente considerando la mejoría inmediata tras la resección tumoral de la masa.

En resumen, se presenta la primera descripción nacional de un paciente joven que debuta con trombocitopenia severa que tras su estudio se demuestra neoplasia testicular de células germinales con metástasis cardíaca y gran compromiso de las cavidades derechas con respuesta exitosa a la terapia médica y quirúrgica.

\section{Referencias:}

1. VOHRA A, SAIZ E, DÁVILA E, BURKLE J. Metastatic Germ Cell Tumor to the Heart Presenting with Syncope. Clin Cardiol. Review. 1999; 22: 429-33.

2. GÜRSU Ö, ISBIR S, AK K, ÖZBEN B, TÜRKÖZ HK, DAL $D$, et al. Testicular Germ Cell Tumor Metastatic to the Right Atrium. J Card Surg. 2011; 26: 276-9.

3. AVASTHI R, CHAUDHARY SC, MOHANTY D, MISHRA K. Testicular Mixed Germ Cell Tumor Metastasizing to Heart. J Assoc Physicians India. 2008; 56: 812-5.

4. BREDAEL JJ, VUGRIN D, WHITMORE WF JR. Autopsy findings in 154 patients with germ cell tumors of the testis. Cancer. 1982; 50: 548-51.

5. JOHNSON DE, APPELT G, SAMUELS ML, LUNA M. Metastases from testicular carcinoma. Study of 78 autopsied cases. Urology. 1976; 8: 234-9.

6. DECK AJ, TRUE LD, Higano CS. Tricuspid valve metastasis from testicular carcinoma: a case report and review of the literature. Urology. 2000; 56: 330. Review.

7. MAY M, FINKBEINER Y, GUNIA S, SEEHAFER M, KNÖRIG J, HETZER R. Metastasizing testicular germ-cell tumor with infiltration of the right heart: indication for primary metastasectomy. Heart Vessels. 2006; 21: 63-5.

8. FISHMAN AD, HOFFMAN A, VOLTERRA F, FRYMUS M, GENTILLUCI M. Intracaval and intracardiac metastatic nonseminomatous germ cell tumor: a rare cause of hemolytic anemia and thrombocytopenia. Cancer Invest. 2002; 20: 996-1001. Review.

9. LIU JX, EFTIMIE B, MORTIMER J. Intracardiac metastasis of germ cell tumor complicated by pulmonary hypertension and thrombocytopenia. J Clin Oncol. 2007; 25: 3547-9.

10. KROLL MH, HELLUMS JD, MCINTIRE LV, SCHAFER AI, MOAKE JL. Platelets and shear stress. Blood. 1996; 88: 152541. Review. 